\title{
Can the neutrophil/lymphocyte ratio (NLR) have a role in the diagnosis of coronavirus 2019 disease (COVID-19)?
}

\author{
(D)Ahmet Nalbant ${ }^{1}$ \\ (iD) Tezcan Kaya ${ }^{1}$ \\ (iD) Ceyhun Varim ${ }^{\mathbf{1}}$ \\ (D) Selçuk Yaylaci' \\ (iD) Ali Tamer ${ }^{1}$ \\ Hakan Cinemre ${ }^{1}$
}

1. Sakarya University School of Medicine Departments of Internal Medicine.

http://dx.doi.org/10.1590/1806-9282.66.6.746

\section{SUMMARY}

OBJECTIVE: The present study aimed to investigate the role of neutrophil/lymphocyte ratio (NLR), an inflammation marker, complete blood count, and biochemical parameters in the diagnosis of COVID-19.

METHODS: A total of 80 patients who had been hospitalized in the internal medicine clinic were enrolled in the study. The cases were allocated into two groups, i.e., COVID (+) and (-), based on real-time reverse transcription-polymerase chain reaction. The demographic, clinical, and laboratory [NLR, platelet/lymphocyte ratio (PLR), complete blood count, biochemistry, and serology] data of the patients were retrospectively obtained from the hospital data management system.

RESULTS: NLR and fever levels were found to be higher in COVID-19 $(+)$ cases $(P=0.021, P=0.001$, respectively). There was no difference between males and females with regard to COVID-19 positivity $(P=0.527)$. Total bilirubin levels were found to be lower in COVID-19 $\left(^{+}\right)$cases $(P=0.040)$. When the ROC analysis was carried out for NLR in COVID-19 (+) cases, the AUC value was found to be 0.660 ( $P=0.021$ ), sensitivity as $69.01 \%$, specificity as $65.40 \%, L R+: 1.98$ and $L R-: 0.48, P P V: 80.43$, and NPV: 50.00, when the NLR was $\geq 2.4$. The risk of COVID-19 was found to be 20.3-fold greater when NLR was $\geq 2.4$ in the logistic regression ( $P=0.007$ ).

CONCLUSION: NLR is an independent predictor for the diagnosis of COVID-19. We also found that fever and total bilirubin measurements could be useful for the diagnosis of COVID-19 in this population.

KEYWORDS: Coronavirus Infections. Coronavirus. Fever. Lymphocytes. Neutrophils.3+q

\section{INTRODUCTION}

Coronaviruses (CoVs) are single-chain, enveloped RNA viruses. They do not contain the RNA polymerase enzyme; however, they encode this enzyme in their genome. They are defined as $\mathrm{CoV}$ due to the protrusions on their surface (Latin: corona=crown).
Coronaviruses belong to the Orthocorona-virinae sub-family and are classified as four types (alpha, beta, gamma, and delta CoVs) and multiple subspecies. Coronavirus 2019 is within the beta-coronavirus $2 \mathrm{~b}$ strain. The genomes of the beta-coronaviridae were 
shown to be closely related to the bat SARS-like coronavirus ${ }^{2}$. This type of virus may be found in humans, bats, pigs, cats, dogs, remnants, and winged animals ${ }^{3}$. Coronaviruses are a large virus family that may lead to self-limited, mild, and common infections like the common cold, and also more severe infections like Severe Acute Respiratory Syndrome (SARS) ${ }^{4}$ and Middle East Respiratory Syndrome (MERS) ${ }^{5}$. These viruses may lead to clinical conditions with various degrees of respiratory, enteric, hepatic, nephritic, and neurological involvement.

Pneumonia cases with unknown etiology and of suggested viral origin were reported in Wuhan, Hubei, China on 31 December 2019. The virus was shown in workers of the seafood wholesale market where different animal types are sold. The patients exhibited fever, dyspnea, cough, and, radiologically, bilateral pneumonic infiltrations ${ }^{6}$. Death usually occurred in individuals who were elderly or who had comorbid systemic diseases (hypertension, diabetes mellitus, cardiovascular diseases, cancer, chronic pulmonary diseases, and other immune-suppressive conditions) ${ }^{7,8}$.

The pathophysiology of the high pathogenicity of this unusual highly contagious SARS-CoV2 could not be fully understood yet. Inflammation plays an important role in infectious diseases. Accumulating evidence has shown the importance of inflammation in the progression of viral pneumonia, including in coronavirus disease 2019 (COVID-19) cases $^{8}$. Pro-inflammatory cytokines have been shown to increase in sera of patients with pulmonary inflammation'. The white blood cell (WBC) count, neutrophil, lymphocyte count, neutrophil/lymphocyte ratio (NLR), and platelet/lymphocyte ratio (PLR) are markers of systemic inflammation ${ }^{10,11}$. These markers are useful predictors for the prognosis and follow-up of patients with viral pneumonia. NLR is a very useful, rapid, and inexpensive indicator, the significance of which has been shown in bacterial pneumonia ${ }^{12}$ and viral infections ${ }^{13}$.

This retrospective, single-center study was conducted to investigate the complete blood count parameters, NLR, PLR, C-reactive protein (CRP), and the other infection bio-markers and biochemical data of a total of 80 COVID-19 positive and negative cases.

\section{METHODS}

A total of 80 patients who had been hospitalized at the medical clinic between 01 April 2020 and 25 April 2020 and tested for COVID-19 with real-time reverse transcription-polymerase chain reaction (rRT-PCR) were enrolled in the study. The nasal and pharyngeal swabs of all patients were obtained. Isolated patient samples that were obtained with VNAT viral transport and brought to the molecular virology laboratory were examined using the Biospedy (Bioeksen, Turkey) rRT-PCR kit provided by the Ministry of Health of Turkey. The patients whose rRTPCR results were positive were regarded as COVID-19 $(+)$, and those whose rRT-PCR results were negative twice with a 48-hour interval were regarded as COVID-19 (-). Hospital records (demographic, clinical, and laboratory data) of the cases above 18 years were analyzed retrospectively. The patients were divided into two groups, i.e., COVID-19 (+) and COVID-19 (-). Neutrophil, lymphocyte, platelets, MPV, hemoglobin, and CRP values of all patients were recorded, and the NLR and PLR values were calculated. The reports from the thoracic computed tomographies were obtained from the data management system. Serum urea, creatinine, total cholesterol, triglyceride, low-density lipoprotein (LDL)-cholesterol, high-density lipoprotein (HDL)-cholesterol, aspartate aminotransferase (AST), alanine aminotransferase (ALT), and albumin were analyzed using the kinetic alkaline picrate method with the Architect C 16000 (Abbott) device at the biochemistry laboratory of the hospital. The complete blood count parameters were examined with the Celldyn 3700 device. Ethics committee approval was obtained from the Ministry of Health of the Turkish Republic and the Sakarya University Medical School (No: 715224737050.01.04/131; April 04, 2020).

\section{STATISTICAL ANALYSIS}

Data analysis was performed by using statistical software (SPSS, version 10.0 [SPSS Inc, Chicago, IL]. Normally distributed data were compared by one-way analysis of variance, and non-normally distributed data were compared via the Mann-Whitney $\mathrm{U}$ test. Categorical associations were evaluated by using the $\chi 2$ test and multiple logistic regression. The goodness of fit was determined by using the Nagelkerke $\mathrm{R}^{2}$ and Hosmer-Lemeshow goodnessof-fit test. The performance of NLR was assessed using receiver operating characteristic (ROC) curve analysis and by calculating the area under the curve (AUC) of the ROC curves. Statistical significance was defined as $\mathrm{P} \leq 0.05$. 


\section{RESULTS}

Of the total 80 patients, 39 (49\%) were females and 41 (51\%) were males. COVID-19 was determined to be positive in 54 out of the 80 cases $(67.5 \%)$. The mean age (SD) was 53 (18) years for COVID-19 (+) patients and 60 (14) for COVID-19 (-) patients, and the difference was not statistically significant $(\mathrm{F}=3.029 ; \mathrm{P}=0.086)$. Similarly, there was no difference between the groups concerning gender $(\chi 2=0.400 \mathrm{P}=0.527)$. Fever was present in $41 \%$ of COVID-19 (+) cases. There was a significant difference between the groups concerning HDL-cholesterol values ( $\mathrm{F}=4.984 ; \mathrm{P}=0.031)$. The rates of fever, lactate, and ferritin levels were significantly higher in COVID-19 (+) cases compared to COVID-19 (-) cases (Mann-Whitney U=390.0, $\mathrm{P}<0.001 ; 152.0, \mathrm{P}=0.040$; 202.5, $\mathrm{P}=0.046 ; 396.0, \mathrm{P}=0.008$, respectively). The rates of total bilirubin level were significantly lower in COVID-19 (+) cases (Mann-Whitney $\mathrm{U}=152.0$, $\mathrm{P}=0.040$ ). While the NLR, PLR, and CRP values were significantly higher (Mann-Whitney U 477.5, $\mathrm{P}=0.021$; 508.0, $\mathrm{P}=0.046$; 448.5, $\mathrm{P}=0.012$, respectively), the lymphocyte count was significantly lower (Mann-Whitney U 419.0, $\mathrm{P}=0.004)$ in COVID-19 (+) cases compared to COVID-19 (-) cases. There was no difference between COVID-19 (+) and (-) cases concerning WBC, neutrophil, platelet count, MPV, and procalcitonin. The demographic and laboratory characteristics of patients infected with and without COVID-19 are shown in Table - I. The mean neutrophil/lymphocyte ratio and fever in COVID-19 (+) and (-) cases are displayed in Figure 1. The effect of NLR on the diagnosis of COVID-19 was analyzed by ROC curve and AUC and was found to be significant (AUC:0.660; P=0.021, 95\% CI 0.538 to 0.783 ) (Fig.2). Sensitivity, specificity, positive predictive value, negative NPV, LR+, LR- values, and the disease prevalence for NLR $\geq 2.4$ were $69.01 \%, 65.40 \%$, $80 \%, 50 \%, 1.98,0.48$ and $67.5 \%$, respectively. The effect of fever on the diagnosis of COVID-19 was analyzed by

TABLE 1. DEMOGRAPHIC AND LABORATORY CHARACTERISTICS OF PATIENTS INFECTED WITH AND WITHOUT COVID-19.

\begin{tabular}{|c|c|c|c|}
\hline Indicators & Covid-19 (+) n=54 & Covid $-19(-) n=26$ & P-value \\
\hline Mean age (SD), year & $53(18)$ & $60(14)$ & 0.086 \\
\hline Men & 29 & 12 & 0.635 \\
\hline Women & 25 & 14 & 0.347 \\
\hline Lymphocyte (IR),K/uL & $1.3(0.7)$ & $2.0(1.0)$ & 0.004 \\
\hline NLR median (IR) & $4.7(2.8)$ & $2.9(1.7)$ & 0.021 \\
\hline Platelet (IR), K/uL & $183(21)$ & $221(43)$ & 0.681 \\
\hline$M P V(S D), f l$ & $9(1.3)$ & $9.2(1.1)$ & 0.987 \\
\hline Hemoglobin (SD), gr/dL & $12.4(1.7)$ & $11.5(1.8)$ & 0.033 \\
\hline PLR median (IR) & $141(22)$ & $104(14)$ & 0.046 \\
\hline Kreatinin $\mathrm{mg} / \mathrm{dL}$ & $0.8(0.6)$ & $0.6(0.4)$ & 0.703 \\
\hline Total Cholesterol (SD), mg/dL & $151(34)$ & $158(49)$ & 0.197 \\
\hline Triglycerides (IR), mg/dL & $115(45)$ & $80(23)$ & 0.120 \\
\hline Low-density lipoprotein (SD), mg/dL & $95(24)$ & $109(29)$ & 0.099 \\
\hline High-density lipoprotein (SD), mg/dL & $30(9)$ & $38(14)$ & 0.031 \\
\hline Alanine aminotransferase (IR), $U / L$ & $33(27)$ & $25(22)$ & 0.170 \\
\hline Aspartate (IR), U/L & $33(9)$ & $28(8)$ & 0.015 \\
\hline Albumin (SD), mg/dL & $3.4(0.5)$ & $3.4(0.6)$ & 0.934 \\
\hline Protrombin zamanı (SD), s & $12.7(1.4)$ & $12.3(1.2)$ & 0.304 \\
\hline INR (IR) & $1.2(0.3)$ & $1.0(0.2$ & 0.016 \\
\hline Activated partial thromboplastin time (SD) , s & $25(2.8)$ & $26(3.4)$ & 0.567 \\
\hline $\mathrm{LDH}(\mathrm{IR}), \mathrm{U} / \mathrm{L}$ & $322(17)$ & $211(15)$ & 0.016 \\
\hline Creatine kinase (IR), U/L & $64(14)$ & $71(18)$ & 0.039 \\
\hline Ferritin $(I R) \mu g / L$ & $503(131)$ & $108(51)$ & 0.008 \\
\hline Total bilirubin (IR)mg/dL & $0.64(0.1)$ & $0.9(0.2)$ & 0.040 \\
\hline d-Dimer (IR), ugFEU/L & $633(176)$ & $570(150)$ & 0.934 \\
\hline $\operatorname{CRP}(\mathrm{IR}) \mathrm{mg} / \mathrm{L}$ & $89(88)$ & $3.1(1.1)$ & 0.012 \\
\hline Procalcitonin (IR) & $0.09(0.2)$ & $0.05(0.1)$ & 0.945 \\
\hline Laktat (IR) mmol/L & $1.7(1.5)$ & $1.4(1.1)$ & 0.046 \\
\hline Thorax computorize tomography (typical viral pneumonia sign) & 10 & 2 & 0.204 \\
\hline
\end{tabular}


ROC curve and AUC and was found to be significant (AUC:0.722; $\mathrm{P}=0.001,95 \%$ CI 0.606 to 0.838). Sensitivity, specificity, positive predictive value, negative $\mathrm{NPV}, \mathrm{LR}+, \mathrm{LR}-$ values, and the disease prevalence for fever $\geq 36.8$ were $66.67 \%, 76.92 \%, 86 \%, 43 \%, 2.98,0.43$ and $67.5 \%$, respectively.

We built a logistic regression model including NLR $\geq$ 2.4 , temperature $\geq 36.8$, and serum total bilirubin as free predictors of a Covid-19 positive diagnosis. According to our model, the odds ratio for a covid-19-positive result was 20.3 and 10.5 when NLR was $>2.4$ and temperature was $>36.8(\mathrm{~B}=3.011$, Standart Error $=1.324$, Wald=5.170, Odds ratio=20.3, $\mathrm{P}=0.023$ for NLR; $\mathrm{B}=2.356$, Standart Error $=1.079$, Wald $=4.768$, Odds ratio=10.5, $\mathrm{P}=0.029$ for fever and $B=-7.726$, Standart Error $=3.141$, Wald=6.049, Odds ratio $=0.0, \mathrm{P}=0.014$ for serum total bilirubin). The decrease of total serum bilirubin was significant for a covid-19-positive result, but without affecting the odds ratio. Nagelkerke $\mathrm{R}^{2}$ was $65 \%$.

\section{DISCUSSION}

In the present study, we reported the cohort of 54 COVID-19 (+) cases and 26 COVID-19 (-) cases confirmed with laboratory tests. NLR and fever were found tobe significantly higher in COVID-19 cases. Total bilirubin levels were found to be lower in COVID19 cases. There was no difference between COVID-10 $(+)$ and $(-)$ cases concerning age and gender.

FIGURE 1. MEAN NEUTROPHIL TO LYMPHOCYTE RATIO TEMPERATURE IN PATIENTS WITH AND WITHOUT COVID-19.

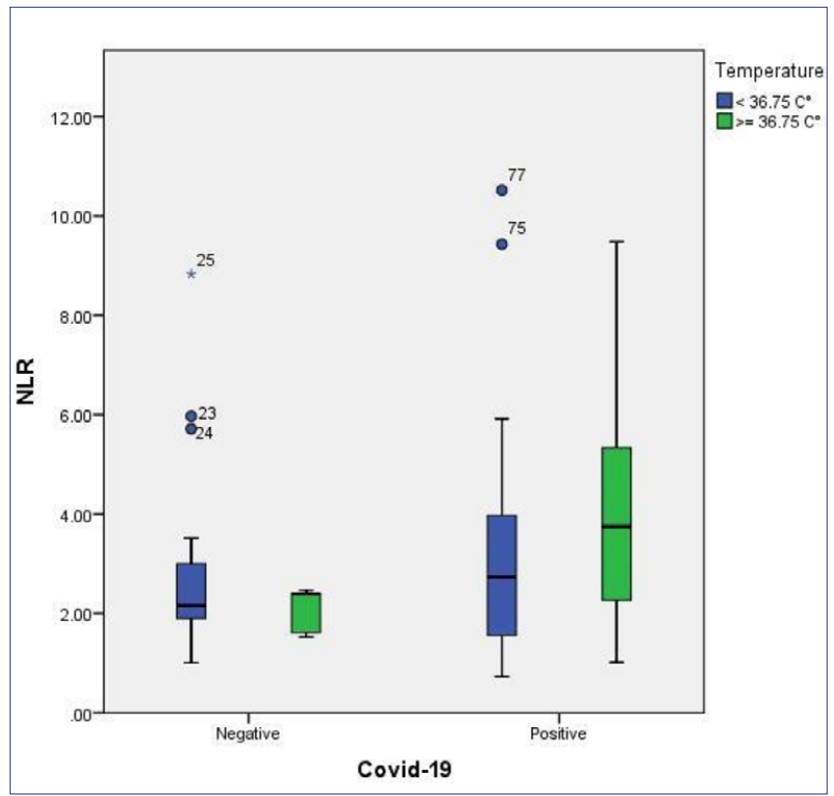

Fever is among the most important clinical manifestations of $\mathrm{CoV}$ infections. In a study reported in the Lancet, fever was detected in $83 \%$ of the cases with COVID-19 pneumonia ${ }^{14}$; this rate was found to be $43.8 \%$ in another study ${ }^{7}$. The rate of fever was found to be $41 \%$ in our study. If the definition of case surveillance is mainly focused on the detection of fever, patients may be overlooked in the absence of fever, since fever was not detected in about half of the patients at the beginning. We determined a significant difference between COVID-19 (+) and (-) cases concerning fever. The risk of COVID-19 was found to be 10.5-fold greater when the fever was $\geq 36.8$ degrees. Fever and CRP are not only systemic markers of inflammation but also mediators of inflammatory factors ${ }^{15}$. CRP was found to be high in COVID-19 patients in a previous study ${ }^{16}$. We also found CRP to be significantly high in our study.

The decrease of total serum bilirubin was significant for covid-19-positive results but without affecting the odds ratio. Also, AST levels were significantly higher in COVID-19 cases; however, this increase was not observed for ALT. This was compatible with a study in China ${ }^{1718}$. This elevation may be related to viral load and changes in the liver synthesis capacity. Other causes of changes in liver function include ACE2-mediated direct viral infection of hepatocytes or critically-ill status and immune-mediated injury.

Thrombocytopenia is another pathological finding that could be detected in a complete blood count ${ }^{19}$.

FIGURE 2. RECEIVER OPERATING CHARACTERISTIC CURVE FOR NEUTROPHIL TO LYMPHOCYTE RATIO IN PATIENTS WITH OR WITHOUT COVID-19.

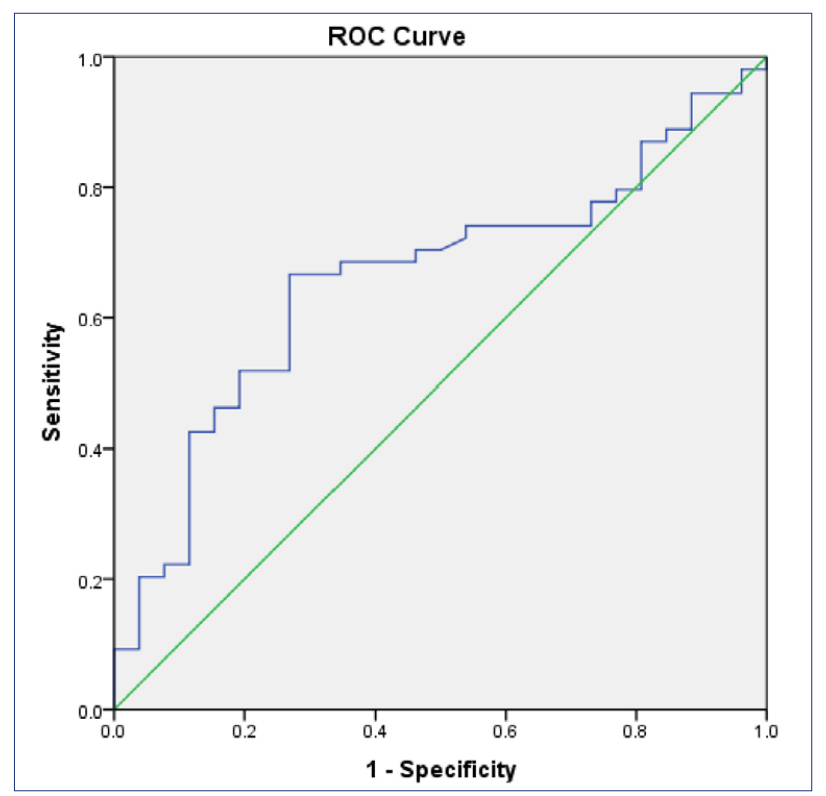


Thrombocytopenia was detected in our study, consistent with the previous study; furthermore, PLR was significantly high. The platelet count, dynamic changes during treatment, and PLR were a source of concern in severe COVID-19 pneumonia cases. It was interpreted that PLR could serve as a novel indicator of the degree of cytokine storm ${ }^{20}$.

In a study conducted in China, no difference was found between severe and moderate cases concerning the WBC count in the correlation analysis, and lymphopenia was reported to develop when the WBC count was normal ${ }^{21}$. Consistent with the previous study, we detected lymphopenia when the WBC and the neutrophil count were normal in hospitalized COVID19 cases.

A decrease was determined in the peripheral blood lymphocyte count of critically ill COVID-19 patients ${ }^{9,14,16}$. Immune cells infiltrate the lungs and lead to unexplained severe lung infections ${ }^{4}$. In a study, the lymphocyte count was found to be $<1.0 \times 10^{9} / \mathrm{L}(9)$. We found the lymphocyte value as $1.3 \times 10^{9} / \mathrm{L}$, consistent with the previous studies.

The human immune response is created by lymphocytes triggered by viral infections ${ }^{22}$. Systemic infections suppress cellular immunity. The novel coronavirus may mainly act on lymphocytes, especially T lymphocytes ${ }^{23}$. The total lymphocytes, CD4+ T cells, CD8+ T cells, B cells, and NK cells decreased in COVID-19 patients, and severe cases had lower levels of these cells than mild cases ${ }^{22,24}$. Therefore, CoV-induced inflammation-related lymphopenia increased NLR. In the only study conducted before ours, the optimal threshold of 3.3 for NLR showed a superior prognostic possibility of clinical symptoms for change from mild to severe ${ }^{7}$. Our study was among the first studies in the literature. We found NLR to be high and the likelihood of COVID-19 was 20-fold greater when NLR was $\geq 2.4$.

The results of rRT-PCR can be obtained in hours; hence the diagnosis and treatment may be delayed.
The shortcomings of the PCR method due to false positive/false negative results from insufficient sampling, insufficient laboratory facilities due to the pandemic, samples collected too early or too late, and the binding sites of primer/probe couples used in the rRT-PCR lead to some difficulties in the diagnosis ${ }^{25}$. However, NLR is a rapid, inexpensive, and useful indicator that could be estimated via the complete blood count. The clinical use of NLR has been shown in bacterial pneumonia ${ }^{12}$ and viral infections ${ }^{13}$. The surveillance of NLR and lymphocyte subsets is helpful in the early screening of critical illness, diagnosis, and treatment of COVID-1977.

The COVID-19 pandemic may spread rapidly from human-to-human. The clinical characteristics of the disease vary among patients. The severity of the condition may be related to the number of immune cells.

\section{CONCLUSION}

In conclusion, we found that NLR was significantly elevated in COVID-19 patients. We also provided a cut-off for this readily available test and showed that patients with NLR $\geq 2.4$ were 20.5 times more likely to have COVID-19 compared to patients whose NLR was $\leq 2.4$. Similarly, the likelihood of COVID-19 was 10.5 -fold greater when fever was $\geq 36.8^{\circ} \mathrm{C}$. This study indicates that high fever and NLR are independent biomarkers for COVID-19 patients. Our findings may also help in the early diagnosis of COVID-19.

\section{Authors contribution}

AN, CV \& SY did data collection and manuscript writing; AN, TK \& HC conceived, designed, and did the statistical analysis \& editing of the manuscript; AT did the review and final approval of the manuscript; AN takes responsibility and is accountable for all aspects of the work, ensuring that questions related to the accuracy or integrity of any part of the work are appropriately investigated and resolved.

\section{RESUMO}

OBJETIVO: O objetivo do presente estudo foi investigar o papel da razão neutrófilos/linfócitos (RNL), um marcador de inflamação, hemograma completo e parâmetros bioquímicos no diagnóstico de COVID-19.

MÉTODOS: Um total de 80 pacientes internados na clínica médica foram incluídos no estudo. Os casos foram alocados em dois grupos, COVID (+) e (-), de acordo com a reação em cadeia da polimerase com transcrição reversa em tempo real. Os dados demográficos, clínicos e laboratoriais [NLR, relação plaquetas / linfócitos ( $P L R)$, hemograma completo, bioquímica e sorologia]) dos pacientes foram obtidos retrospectivamente no sistema de gerenciamento de dados hospitalares. 
RESULTADOS: Os níveis de NLR e febre foram maiores nos casos de COVID-19 (+) ( $P=0,021, P=0,001$, respectivamente). Não houve diferença entre homens e mulheres em relação à positividade para COVID-19 ( $P=0,527)$. Os níveis totais de bilirrubina foram menores nos casos de COVID-19 (+) ( $P=0,040)$. Quando a análise ROC foi realizada para NLR nos casos COVID-19 (+), o valor da AUC foi de 0,660 ( $P=0,021$ ), sensibilidade 69,01\%, especificidade 65,40\%, LR+: 1,98 e LR-: 0,48, PPV: 80,43 e NPV: 50,00 quando o NLR era> 2,4. The risk of COVID-19 was found to be 20.3-fold greater when NLR was $\geq 2.4$ in the logistic regression ( $P=0.007)$.

CONCLUSÃO: NLR é um preditor independente para o diagnóstico de COVID-19. Também concluímos que aferições de febre e bilirrubina total podem ser úteis para o diagnóstico de COVID-19 nesta população.

PALAVRAS-CHAVE: Infecções por Coronavirus. Coronavirus. Febre. Linfócitos. Neutrófilos.

\section{REFERENCES}

1. Zhou Y, Yang Y, Huang J, jiang S, Du L. Advances in MERS-CoV vaccines and therapeutics based on the receptor-binding domain. Viruses. 2019;11(1):60.

2. Tan W, Zhao X, Ma X, Wang W, Niu P, Xu W, et al. A novel coronavirus genome identified in a cluster of pneumonia cases - Wuhan, China 2019-2020. China CDC Weekly. 2020;2(4):61-2. [cited 2020 May 12] Available from: http://weekly.chinacdc.cn/fileCCDCW/journal/article/ ccdcw/2020/4/PDF/Wuhan.pdf

3. Richman DD, Whitley RI, Hayden FG. Clinical virology. 4th ed. Washington: ASM Press; 2017. p.1243-7.

4. Chan IF, Li KS, To KK, Cheng VC, Chen H, Yuen KY. Is the discovery of the novel human betacoronavirus 2c EMC/2012 (HCoV-EMC) the beginning of another SARS-like pandemic? I Infect. 2012;65:477-89.

5. Zaki AM, van Boheemen $S$, Bestebroer TM, Osterhaus AD, Fouchier RA. Isolation of a novel coronavirus from a man with pneumonia in Saudi Arabia. N Engl | Med. 2012;367(19):1814-20.

6. World Health Organization. Novel coronavirus - China. Geneva: World Health Organization; 2020. [cited 2020 May 12]. Available from: https:// www.who.int/csr/don/12-january-2020-novel-coronavirus-china/en/

7. Yang AP, Liu JP, Tao WQ, Li HM. The diagnostic and predictive role of NLR, d-NLR and PLR in COVID-19 patients. Int Immunopharmacol. 2020;84:106504.

8. Zhu N, Zhang D, Wang W, Li X, Yang B, Song J, et al; China Novel Coronavirus Investigating and Research Team. A novel coronavirus from patients with pneumonia in China, 2019. N Engl | Med. 2020;382(8):727-33.

9. Huang $C$, Wang $Y$, Li X, Ren L, Zhao I, Hu Y, et al. Clinical features of patients infected with 2019 novel coronavirus in Wuhan, China. Lancet. 2020;395(10223):497-506.

10. Zahorec R. Ratio of neutrophil to lymphocyte counts: rapid and simple parameter of systemic inflammation and stress in critically ill. Bratisl Lek Listy. 2001;102(1):5-14.

11. Ying HQ, Deng QW, He BS, Pan YQ, Wang F, Sun HL, et al. The prognostic value of preoperative NLR, $d-N L R, P L R$ and LMR for predicting clinical outcome in surgical colorectal cancer patients. Med Oncol. 2014;31(12):305

12. Yoon NB, Son C, Um SI. Role of the neutrophil-lymphocyte count ratio in the differential diagnosis between pulmonary tuberculosis and bacterial community-acquired pneumonia. Ann Lab Med. 2013;33(2):105-10.

13. Qin C, Zhou L, Hu Z, Zhang S, Yang S, Tao Y, et al. Dysregulation of immune response in patients with COVID-19 in Wuhan, China. Clin Infect Dis. 2020; ciaa248
14. Chen N, Zhou M, Dong X, Qu J, Gong F, Han Y, et al. Epidemiological and clinical characteristics of 99 cases of 2019 novel coronavirus pneumonia in Wuhan, China: a descriptive study. Lancet. 2020;395(10223):507-13.

15. Thiele JR, Zeller J, Bannasch H, Stark GB, Peter K, Eisenhardt SU. Targeting $\mathrm{C}$-reactive protein in inflammatory disease by preventing conformational changes. Mediators Inflamm. 2015;2015:372432.

16. Kim ES, Chin BS, Kang CK, Kim NJ, Kang YM, Choi JP, et al; Korea National Committee for Clinical Management of COVID-19. Clinical course and outcomes of patients with severe acute respiratory syndrome coronavirus 2 infection: a preliminary report of the first 28 patients from the Korean Cohort Study on COVID-19. J Korean Med Sci. 2020;35(13):e142.

17. Feng G, Zheng KI, Yan QQ, Rios RS, Targher G, Byrne CD, et al. COVID-19 and liver dysfunction: current insights and emergent therapeutic strategies. | Clin Transl Hepatol. 2020;8(1):18-24.

18. Wong SH, Lui RN, Sung JJ. Covid-19 and the digestive system. J Gastroenterol Hepatol. 2020;35(5):744-8.

19. Zhang G, Zhang J, Wang B, Zhu X, Wang Q, Qiu S. Analysis of clinical characteristics and laboratory findings of 95 cases of 2019 novel coronavirus pneumonia in Wuhan, China: a retrospective analysis. Respir Res. 2020;21(1):74.

20. Qu R, Ling Y, Zhang YH, Wei LY, Chen X, Li XM, et al. Platelet-to-lymphocyte ratio is associated with prognosis in patients with coronavirus disease-19. J Med Virol. 2020;10.1002/jmv.25767.

21. Zhou Y, Zhang Z, Tian I, Xiong S. Risk factors associated with disease progression in a cohort of patients infected with the 2019 novel coronavirus. Ann Palliat Med. 2020;9(2):428-36.

22. Rabinowich $H$, Cohen R, Bruderman I, Steiner Z, Klajman A. Functional analysis of mononuclear cells infiltrating into tumors: lysis of autologous human tumor cells by cultured infiltrating lymphocytes. Cancer Res. 1987;47(1):173-7.

23. Menges T, Engel J, Welters I, Wagner RM, Little S, Ruwoldt R, et al. Changes in blood lymphocyte populations after multiple trauma: association with posttraumatic complications. Crit Care Med. 1999;27(4):733-40.

24. Wang F, Nie J, Wang H, Zhao Q, Xiong Y, Deng L, et al. Characteristics of peripheral lymphocyte subset alteration in COVID-19 pneumonia. I Infect Dis. 2020;221(11):1762-9.

25. Xiao AT, Tong YX, Gao C, Zhu L, Zhang YJ, Zhang S. dynamic profile of rt-per findings from 301 COVID-19 patients in Wuhan, China: a descriptive study. J Clin Virol. 2020;127:104346. 